\title{
HUBUNGAN PROSENTASE LEMAK DAN BERAT BADAN DENGAN AGILITY KLUB PENCAK SILAT NUSANTARA DKI USIA 11-18 TAHUN
}

\author{
Widiastuti $^{1}$, Hendro Wardoyo ${ }^{2}$, hernawan ${ }^{3}$, Sri Nuraini ${ }^{4}$, \\ Ilmu Keolahragaan, Fakultas Ilmu Olahraga, Universitas Negeri Jakarta, Jl. Pemuda \\ No.10, Rawamangun, Jakarta Timur, Indonesia. \\ widiastuti@unj.ac.id, hwardoyo@unj.ac.id, hermawan@unj.ac.id, \\ srinuraini@unj.ac.id
}

\begin{tabular}{l}
\hline \multicolumn{1}{c}{ Info Artikel } \\
\hline Sejarah Artikel: \\
Diterima Juni 2020 \\
Disetujui September 2020 \\
Dipublikasikan Desember 2020
\end{tabular}

\begin{abstract}
Abstrak
Penelitian ini bertujuan untuk mengetahui hubungan prosentase lemak dan berat badan dengan agility klub pencak silat nusantara dki usia 11-18 tahun. Metode penelitian yang digunakan adalah metode kuantitatif dengan studi korelasi, yaitu dengan mengumpulkan data yang diperoleh dari hasil pencatatan dan pengukuran yang terdiri dari Prosentase lemak, berat badan, dan agility. Teknik pengambilan sampel dalam penelitian ini menggunakan teknik random sampling dengan jumlah 100 atlet klub pencak silat remaja, dan menggunakan instrument alat pengukur lemak (fat caliper), timbangan, data diri dan alat tulis, stopwach, peluit, cone atau marker. Hasil yang didapat yaitu terdapatnya hubungan yang positif antara prosentase lemak dengan agility, yang memiliki nilai sebesar 0,550 , dan juga terdapat hubungan yang positif antara berat badan dengan agility, yang memiliki nilai sebesar 0,415 . Terdapat hubungan yang positif antara prosentase lemak dan berat badan dengan agility yang memiliki nilai sebesar 0.601. Berdasarkan hasil penelitian, dapat disimpulkan terdapatnya hubungan yang signifikan antara berat badan, prosentase lemak dengan kelincahan (agility) pada seorang atlet pencak silat.
\end{abstract}

Keyword:

Berat badan, Kelincahan.

Pencak silat, Lemak, Prosentase lemak

\section{Abstrack}

This study aims to determine the relationship between the percentage of fat and weight with the agility of the Indonesian martial arts club aged 11-18 years. The research method used is a quantitative method with correlation studies, namely by collecting data obtained from the results of recording and measurement consisting of the percentage of fat, weight, and agility. The sampling technique in this study used a random sampling technique with a total of 100 teenage martial arts club athletes, and used fat caliper instruments, scales, personal data and stationery, stopwach, whistle, cone or marker. The results obtained are that there is a positive relationship between the percentage of fat with agility, which has a value of 0.550, and there is also a positive relationship between body weight and agility, which has a value of 0.415. There is a positive relationship between the percentage of fat and weight with agility which has a value of 0.601 . 
Based on the results of the study, it can be concluded that there is a significant relationship between body weight, fat percentage with agility (agility) in a martial arts athlete..

(C) 2020 Universitas Suryakancana

Alamat korespondensi:

E-mail: widiastuti@unj.ac.id,

\section{PENDAHULUAN}

Lemak merupakan salah satu unsur gizi yang paling utama bagi tubuh seseorang. Banyak orang yang mempercayai bahwa salah satu faktor yang dapat membuat gemuk yaitu karena faktor mengkonsumsi makanan yang tinggi lemak sehingga akan ada penumpukan lemak di tubuh dan juga banyak yang beranggapan bahwa salah satu cara untuk membakar lemak yaitu dengan mengurangi konsumsi makanan yang tinggi akan lemak, dengan demikian akan mendapatkan badan yang ideal dan seluruh komponen kesegaran jasmani akan meningkat dan optimal. Oleh karena (MS. Taufik, 2019) itu diperlukan makanan dengan komposisi yang seimbang perhari nya dan olahraga yang teratur akan meningkatkan kebugarannya akan terjaga dengan baik.

Seseorang tentunya tidak ingin memiliki berat badan yang berlebih yang diakibatkan oleh penimbunan lemak dalam tubuh yang dapat menyebabkan gangguan pada metabolisme tubuh dan kesegaran jasmani salah satunya adalah kelincahan atau agility. Seseorang yang memiliki berat badan yang berlebih maka akan berkurang juga tingkat kelincahan atau agility nya.
Menurut Harsono dalam Riswanda (2016) orang yang lincah adalah orang yang mempunyai kemampuan untuk merubah arah dan posisi tubuh dengan cepat dan tepat pada waktu yang sedang bergerak tanpa kehilangan keseimbangan dan kesadaran akan posisi tubuhnya. Sedangkan menurut Kamus Besar Bahasa Indonesia lincah berarti selalu bergerak, tidak dapat diam, tidak tenang, tidak tetap (Munandar et al., 2020). Sehingga seseorang tersebut selalu ingin melakukan gerakan yang sesuai dengan tingkat kesadaran dimana posisi tubuhnya berada.

Pencak silat merupakan cabang olahraga bela diri full body contact yang dikategorikan dalam olahraga berat dimana tubuh membutuhkan energi yang cukup banyak untuk menghasilkan kondisi fisik yang prima dalam menunjang teknik dan taktik. Pencak lebih merujuk pada segi lahiriah, sedangkan Silat adalah gerak serang bela yang erat hubungannya dengan rohani, sehingga dapat menghidup suburkan naluri, menggerakkan hati nurani manusia dan langsung menyerah kehadirat Tuhan Yang Maha Esa. Silat lebih menunjuk pada wujud rohaniah. 
Dalam pertandingan pencak silat terdapat beberapa kategori yaitu kategori tanding dan kategori seni. Untuk kategori tanding nomor tandingnya disesuaikan dengan berat badan dan untuk kategori seni sesuai nomor nya seni tunggal, seni ganda, dan seni beregu. Dalam pertandingan pencak silat kategori tanding bermain dalam waktu 2 menit bersih atau kotor sebanyak 3 babak. Dalam artian jika bermain 2 menit kotor maka atlet yang bertanding akan bermain selama 2 menit dengan waktu yang terus berjalan. Sedangkan 2 menit bersih atlet yang bertanding akan bermain selama 2 menit dengan waktu yang dihentikan ketika wasit melerai pada saat atlet bertanding melebihi 6 serangan dan waktu pertandingan akan dimulai ketika wasit melanjutkan pertandingan.

Pencak silat merupakan cabang olahraga yang erat sekali hubungannya dengan kelincahan dan berat badan, kelincahan dapat dillatih dengan program latihan yang sesuai untuk peningkatan kelincahan, dengan memiliki kelincahan yang bagus seorang pesilat akan bermain dengan teknik yang leluasa, sehingga dapat menunjang tingkat prestasi dalam pertandingan.

Kategori tanding sangat erat hubungannya dengan kelincahan dan berat badan, karena kategori tanding memiliki beberapa kelas yang harus sesuai dengan berat badan yang telah ditentukan per kelasnya. Seorang atlet yang masuk kategori kelas ringan harus memiliki kecepatan dan kelincahan yang baik, sebelum melakukan pertandingan akan melakukan penimbangan berat badan terlebih dahulu, jika seorang atlet tidak sesuai berat badannya dengan kelas yang telah ditentukan, maka seorang atlet tersebut dinyatakan over weight atau kelebihan berat badan dan akan di diskualifikasi, sehingga tidak dapat mengikuti pertandingan pencak silat.

Seorang atlet pencak silat perlu menjaga berat badan agar sesuai dengan kategori pertandingan. Kadar lemak dalam tubuh dapat diukur dengan menggunakan fatt calliper (alat pengukur lemak). Kebanyakan atlet pencak silat ingin menurunkan berat badan secara singkat, dengan menggunakan jaket dan lari sebelum

\section{METODE}

Metode penelitian yang digunakan adalah metode kuantitatif dengan studi korelasi,yaitu suatu penelitian yang mengumpulkan data yang diperoleh dari hasil pencatatan dan pengukuran yang terdiri dari Prosentase lemak, berat badan, dan agility. Penelitian korelasi adalah suatu penelitian yang melibatkan tindakan pengumpulan data guna menentukan, apakah ada hubungan dan tingkat hubungan antara dua variabel atau lebih.

Populasi sampel penelitian ini adalah atlet club pencak silat nusantara dki Jakarta usia 11-18 tahun 
60 | Widiastuti $^{1}$, Hendro Wardoyo ${ }^{2}$, Iwan Setiawan ${ }^{3}$, Sri Nuraini ${ }^{4}$

Hubungan Prosentase Lemak dan Berat Badan Dengan Agility Klub Pencak Silat Usia 11-18

Adapun desain penelitiannya dapat digambarkan sebagai berikut

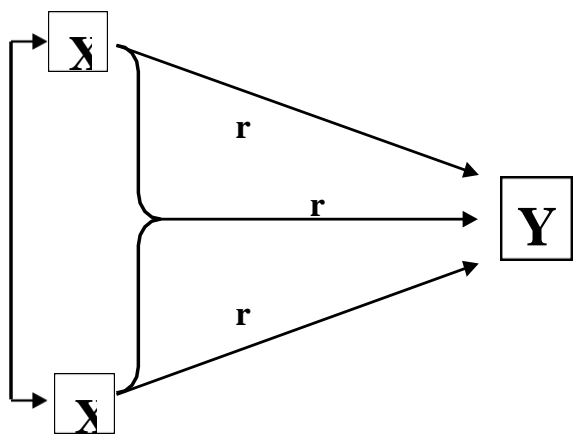

Dalam penelitianini, teknik yang digunakan dalam pengambilan sampel adalah Purposive Sampling. Purposive Sampling adalah teknik penentuan sampel dengan pertimbangan tertentu.

Adapun tahapan kriteria pengambilan sampel adalah sebagai berikut:

Berjenis kelamin laki-laki dan perempuan 100 orang dan merupakan atlet klub usia remaja dan dewasa.

Atlet Bersedia mengikuti tes dan latihan untuk mengetahui lemak, berat badan dan Agility.

Atlet harus bersedia untuk selalu di monitoring tentang keadaannya.

Tidak sedang melakukan program lain

\section{HASIL DAN PEMBAHASAN}

Pengumpulan data pada saat penelitian bertujuan untuk dijadikan sebagai data utama yang diperoleh setelah melakukan test Prosentase Lemak dan Berat badan dengan Agility, yaitu didapat data sebagai berikut :

\begin{tabular}{|l|l|l|l|}
\hline Variabel & $\begin{array}{l}\text { Prosentase } \\
\text { lemak }\end{array}$ & $\begin{array}{l}\text { Berat } \\
\text { badan }\end{array}$ & Agility \\
\hline $\begin{array}{l}\text { Nilai } \\
\text { Tertinggi }\end{array}$ & 33.10 & 93.40 & 18.20 \\
\hline Nilai & 8.10 & 25.60 & 9.91 \\
Terendah & & 52.97 & 13.27 \\
\hline Rata-rata & 19.29 & 12.79 & 2.01 \\
\hline Standar \\
Deviasi & 7.25 & & \\
\hline Nilai & 19.14 & 52.88 & 13.10 \\
tengah & & & \\
\hline
\end{tabular}

Tabel 4.1. Deskripsi Data Penelitian Hubungan Prosentase Lemak dan Berat Badan dengan Agility Deskripsi data pada penelitian ini meliputi nilai tertinggi, nilai rata-rata, standar deviasi, nilai tengah dan distribusi frekuensi, serta histogram dari masing-masing variabel.

\section{Pengolahan Data}

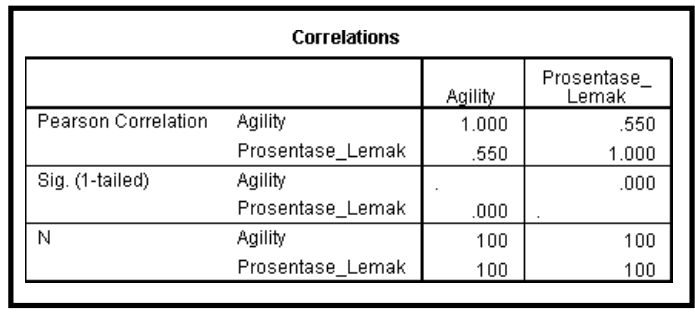

Gambar 4.5 output nilai koefisien

korelasi ry 1 
61 Widiastuti $^{1}$, Hendro Wardoyo ${ }^{2}$, Iwan Setiawan ${ }^{3}$, Sri Nuraini ${ }^{4}$

Hubungan Prosentase Lemak dan Berat Badan Dengan Agility Klub Pencak Silat Usia 11-18

Berdasarkan gambar 4.5 output nilai koefisien korelasi ry1 didapat besar nilai koefisien korelasi antara prosentase lemak (X1) dengan Agility (Y) sebesar

0.550. Nilai koefisien korelasi tersebut mengartikan bahwa hubungan antara prosentase lemak (X1) dengan Agility

(Y) adalah cukup kuat.

\begin{tabular}{|ll|r|r|}
\hline \multicolumn{4}{|c|}{ Correlations } \\
\hline & & \multicolumn{1}{|c|}{ Agillity } & Berat_Badan \\
\hline Pearson Correlation & Agility & 1.000 & .415 \\
& Berat_Badan & .415 & 1.000 \\
\hline Sig. (1-tailed) & Agility & & .000 \\
& Berat_Badan & .000 & \\
\hline $\mathrm{N}$ & Agility & 100 & 100 \\
& Berat_Badan & 100 & 100 \\
\hline
\end{tabular}

Gambar 4.7 output nilai koefisienkorelasi ry2

Berdasarkan gambar 4.7 output nilai koefisien korelasi ry2 didapat besar nilai koefisien korelasi antara prosentase lemak (X2) dengan Agility

(Y) sebesar 0.415. Nilai koefisien korelasi tersebut mengartikan bahwa hubungan antara prosentase lemak (X2) dengan Agility (Y) adalah cukup kuat.

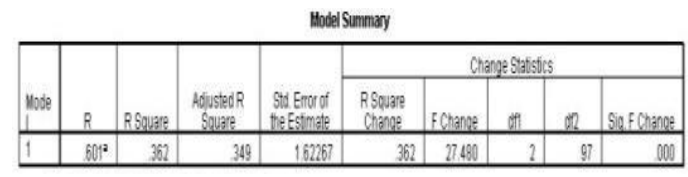

Gambar 4.9 output nilai koefisien korelasi ry 12

Berdasarkan gambar 4.3 output nilai koefisien korelasi ry12 didapat besar nilai koefisien korelasi antara prosentase lemak (X1) dan berat badan (X2) dengan Agility (Y) sebesar 0.601. Nilai koefisien korelasi tersebut mengartikan bahwa terdapat hubungan yang positif antara prosentase lemak (X1) dan berat badan (X2) dengan Agility (Y)

\section{SIMPULAN}

Berdasarkan hasil penelitian yang diperoleh, maka dapat disimpulkan bahwa Hubungan Prosentase Lemak Dan Berat Badan Dengan Agility Klub Pencak Silat Nusantara Dki Usia 11-18 Tahun, adalah sebagai berikut :

Terdapat hubungan yang nyata antara prosentase lemak dengan agility, yang memiliki nilai sebesar 0,550 sehingga dapat dinyatakan cukup kuat hubungann antara prosentase lemak dan agility.

Terdapat hubungan yang nyata antara berat badan dengan agility,yang memiliki nilai sebesar 0,415 sehingga dapat dinyatakan cukup kuat hubungann antara berat badan dan agility.

Terdapat hubungan yang nyata antara prosentase lemak dan berat badan dengan agility, yang memiliki nilai sebesar 0.601 sehingga dapat dinyatakan prosentase lemak dan berata badan memiliki hubungan dengan Agility.

Saran

Dari Hasil penelitian ini penulis ingin menyampaikan beberapa saran- saran sebagai berikut :

Diharapkan untuk selalu memperhatikan berat badan sehingga dapat menjaga tubuh agar tetap ideal. 
62 | Widiastuti ${ }^{1}$, Hendro Wardoyo ${ }^{2}$, Iwan Setiawan ${ }^{3}$, Sri Nuraini ${ }^{4}$

Hubungan Prosentase Lemak dan Berat Badan Dengan Agility Klub Pencak Silat Usia 11-18

Melakukan olahraga secara teratur yang berguna untuk menjaga berat badan dan membakar lemak.

\section{DAFTAR PUSTAKA}

Artikel dalam jurnal online :

Daryanto, Z. P., \& Hidayat, K. (2015).

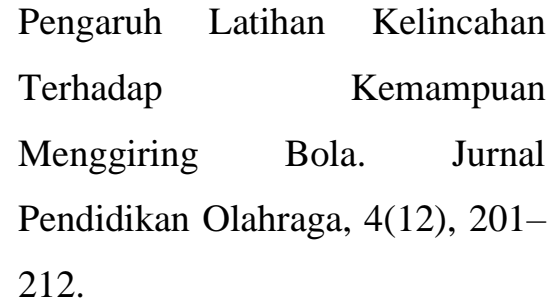

Fentiana, N. (2012). Asupan Lemak Sebagai Faktor Dominan Terjadinya Obesitas Pada Remaja ( 16-18 Tahun ) Di Indonesia Tahun 2010 ( Data Riskesdas (Vol. 2010).

Riswanda Imawan, R. (2016). Pengaruh

Latihan Rope Jump Selama 20

Detik Dengan Metode Interval

Training 1:5 Terhadap Kekuatan

Otot Tungkai. Jurnal Kesehatan

Olahraga, 4(4).

Rudiyanto, waluyo. (2012). Hubungan

Berat Badan Tinggi Badan Dan

Panjang Tungkai Dengan

Kelincahan. Journal of Sport

Sciences and Fitness, 1(2), 26-31

Sartika, R. A. D. (2008). Pengaruh Asam

Lemak Jenuh, Tidak Jenuh dan Asam Lemak Trans terhadap

Kesehatan. Kesmas: National

Public Health Journal, 2(4), 154. https://doi.org/10.21109/kesmas.v 2 i 4.258

Widiyanto. (2005). Metode pengaturan berat badan. Jurnal Penelitian Humaniora, 1(2), 105-117.

Wijayanti, D. (2013). Komposisi Lemak Tubuh. Journal of Chemical Information and Modeling, 53(9), 1689-1699.

https://doi.org/10.1017/CBO97811

07415324.004

Pelana, R. (2018). Weight Loss in Pencak Silat Art Performance Category. Health and Physical Education Attitude, 1(Icsshpe 2017), 111-113.

https://doi.org/10.5220/000705600 1110113

Pradana, T. W., Nasuka, \& Rumini. (2019). The Distinction of Agility Exercise Method and Flexibility Toward The Front Kick Legerity Development of Tapak Suci Pencak Athletes in Temanggung 2018. 8(1), 87-93.

R. Hidayat, R., \& Tomoliyus, M. (2019). The Effects of Plyometric Training and Age on The Agility of Silat Fighters. A

Hendro Wardoyo, J. L. (2014). Pencak Silat Edisi Kedua. Depok: PT Raja Grafindo Persada.

Lubis, J. (2013). Panduan Praktis Penyusunan Program Latihan. 
63 | Widiastuti ${ }^{1}$, Hendro Wardoyo ${ }^{2}$, Iwan Setiawan ${ }^{3}$, Sri Nuraini ${ }^{4}$

Hubungan Prosentase Lemak dan Berat Badan Dengan Agility Klub Pencak Silat Usia 11-18

Depok: PT Raja Grafindo

Persada.

Rusyana Dewi, A. (2015). Hubungan Berat Badan Dan Tinggi Badan Dengan Kelincahan Pemain Futsal Putri Universitas Negeri Yogyakarta. Medikora, XVI(2).

Setiawati, L.(2012). A descriptive study on teacher talk at an EYL classroom. Conaplin Journal : Indonesian Journal of Applied Linguistics, 1(2), hlm.176-178

Sugiyono. (2016). Metode Penelitian Kuantitatif, Kualitatif dan R\&D. Bandung: Alfabeta.

Supardi. (2013). Aplikasi Statitiska dalam penelitian konsep statitiska yang lebih koferensif. Jakarta. Change Pubication.

Widiastuti. (2015). Tes dan Pengukuran Olahraga. Depok: PT Raja Grafindo Persada.
Ramadani, P. (2015). Hubungan Antara Ketebalam Lemak Tubuh Dengan Kondisi Fisik Atlet Karate Pelajar Putra Institute Karate-Do Indonesia Cabang kabupaten semarang tahun 2015

MS. Taufik. (2019). HUBUNGAN

TINGKAT KONSENTRASI

DENGAN KETERAMPILAN

BERMAIN FUTSAL UNIT

KEGIATAN MAHASISWA

FUTSAL UNIVERSITAS

SURYAKANCANA dalam

olahraga. Gladi Jurnal UNJ, 10(02), 68-78. https://doi.org/DOI : https://doi.org/10.21009/GJIK.102.0 1

Munandar, A., Taufik, M. S., \& Putri, R. E. (2020). PENGARUH LATIHAN PLYOMETRICS OTOT

TUNGKAI. Jurnal Maenpo : Jurnal Pendidikan Jasmani Kesehatan Dan Rekreasi, 10, 1-6. 